\begin{tabular}{|c|c|c|c|}
\hline \\
\hline \multicolumn{2}{|c|}{$6^{\mathrm{h}} 35^{\mathrm{m}}$} & Eros & $9^{\ln } \cdot 33$ \\
\hline 7 & 0 & 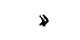 & 9.33 \\
\hline 7 & 32 & 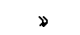 & 9.68 \\
\hline & $5^{8}$ & » & 9.82 \\
\hline 8 & 25 & , & 9.75 \\
\hline
\end{tabular}

Pola, Igor Febr. 15.
Die Höhe von Eros war zum Schluss etwa $34^{\circ}$, die Luft rein, Wind NE, Stärke 5, Bilder ruhig und schön.

Höhl ist in diesen Beobachtungen noch ungeübt, hat sich aber vorher liber die Methode gut informirt und besonders vor Augen gehalten, wie leicht Selbsttäuschung in diesem Falle ist.

Ich beabsichtige diese Beobachtungen fortsetzen zu lassen.

\title{
Der Lichtwechsel des Planeten (433) Eros.
}

Nachdem es in der vergangenen Woche die Witterung nur sporadisch gestattet hatte, neben anderen Beobachtungen den Planeten Eros auf seinen Lichtwechsel hin zu beobachten, konnte ich am $2 \mathrm{i}$. und 22. Februar am 6 zölligen Refractor bis zum Verschwinden der Stelle am Heliometerthurm ( $9^{\mathrm{h}} 54^{\mathrm{m}}$ bez. $10^{\mathrm{h}} 2^{\mathrm{m}}$ Sternzeit) fortlaufende Reihen von Grössenbestimmungen ausführen. Die definitiven Werthe der beobachteten Lichtstärken können erst angegeben werden, wenn klarer Himmel eine schärfere Bestimmung der Ver- gleichsterngrössen ermöglicht hat; inzwischen möchte ich nicht unterlassen zu zeigen, dass die Aenderungen in der Lichtstärke des Planeten unzweifelhaft starke sind und sich von einer überraschend kurzen Periode aus meinen Beobachtungen ergeben.

Febr. 2 I habe ich 39, Febr, 2244 meist auf je 2 bis 3 Vergleichsternanschlüssen beruhende Grössenbestimmungen von Eros erhalten, deren graphische Darstellung folgende vorläufige Werthe der Lichttafel giebt:

\begin{tabular}{|c|c|c|c|c|c|c|c|}
\hline \multicolumn{2}{|c|}{ Sternz. Bonn } & Grösse & \multicolumn{2}{|c|}{ Sternz. Bonn } & Grösse & \multicolumn{2}{|c|}{ Sternz. Bonn } \\
\hline $5^{\mathrm{b}}$ & $\mathrm{o}^{\mathrm{m}}$ & $9 m_{25}$ & & $40^{\mathrm{m}}$ & $9^{\mathrm{m}} \cdot 3$ & $5^{h}$ & $0^{m}$ \\
\hline & 10 & $9 \cdot 3$ & & 50 & $9 \cdot 55$ & & 10 \\
\hline & 20 & 9.4 & 8 & 0 & 9.65 & & 20 \\
\hline & 30 & $9 \cdot 55$ & & 10 & 9.9 & & 30 \\
\hline & 40 & 9.75 & & 20 & 10.4 & & 40 \\
\hline & $5^{\circ}$ & 9.95 & & 30 & 10.9 & & 50 \\
\hline 6 & 0 & 10.35 & & 40 & 10.75 & 6 & 0 \\
\hline & IO & 10.8 & & 50 & 10.4 & & io \\
\hline & 20 & $(10.8)$ & 9 & 0 & 10.3 & & 20 \\
\hline & $3^{\circ}$ & $(\mathrm{r} 0.6)$ & & IO & I 0.1 & & 30 \\
\hline & 40 & $(\mathbf{1} 0.3)$ & & 20 & 9.95 & & 40 \\
\hline & 50 & 9.95 & & 30 & 9.75 & & 50 \\
\hline 7 & $\circ$ & 9.6 & & 40 & 9.5 & 7 & 0 \\
\hline & 10 & 9.2 & & 50 & 9.3 & & 10 \\
\hline & 20 & 9. I & 10 & 0 & $9.15:$ & & 20 \\
\hline & $3^{\circ}$ & 9.15 & & & & & 30 \\
\hline
\end{tabular}

Der mittlere Fehler einer Grössenbestimmung ergiebt sich hieraus $z u \pm 0.075$.

Es haben hiernach stattgefunden:

Februar 2 I.

\begin{tabular}{|c|c|c|c|c|c|c|}
\hline & & $9 \mathrm{~m}_{2}$ & M. Z & Bonn & Grösse & $10^{\mathrm{m}} \cdot 9$ \\
\hline & 9 & 18.8 & 》 & » & $\gg$ & \\
\hline Inin & 10 & 30.8 & 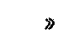 & $\triangleright$ & 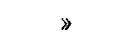 & \\
\hline
\end{tabular}

Bonn, Igor Febr. 24.

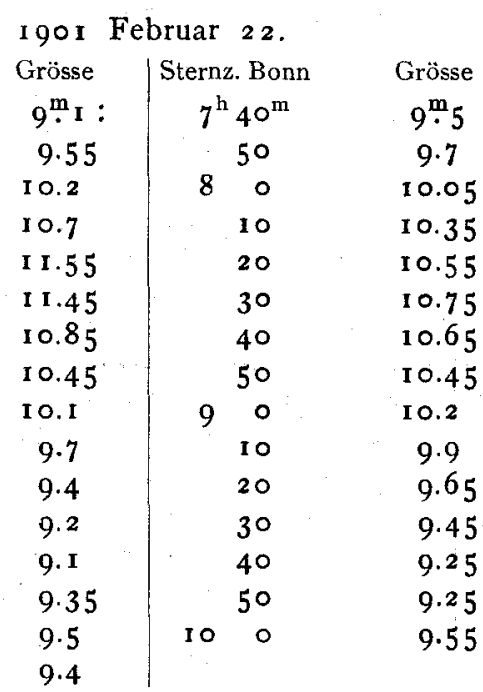

Februar 22.

\begin{tabular}{|c|c|c|c|c|c|c|}
\hline Minimum & & $35^{\mathrm{m}} \cdot 6$ & M. Z & Bonn & Grösse & $\mathrm{II}^{\mathrm{m}}$ \\
\hline $\mathrm{Ma}$ & 8 & 50.3 & $\gg$ & ॥ & » & 9 . \\
\hline Mir & 10 & 22.1 & $»$ & " & $\gg$ & 10. \\
\hline Maxin & I I & $3^{6.4}$ & 》 & $》$ & 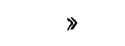 & \\
\hline
\end{tabular}

Die Periodenlänge aus Maximis und Minimis hat hiernach den vorläufigen Werth $2^{\mathrm{h}} \cdot 6 \mathrm{I}$.

\section{Spectralanalytische Beobachtungen über die Nova Persei}

angestellt auf dem Astrophysikalischen Observatorium bei Potsdam am 23. Februar igor.

Die Nova wurde von mir und Prof. Lohse am Schröder' schen Refractor von $30 \mathrm{~cm}$ Oeffinung und von Dr. Hartmann am Leitfernrohr des grossen Refractors beobachtet. Sie er. schien etwas heller als Capella und zeigte ein continuirliches Spectrum Classe I, Blau und Violett auffallend hell. Mit
Ocularspectroskopen war keine Spur von Linien, weder hellen noch dunklen, zu erkennen.

Dr. Hartmann hat am $80 \mathrm{~cm}$ Refractor zwei Aufnahmen des Spectrums mit Spectrograph I (schwache Dispersion) angefertigt, auf denen eine Reihe von matten breiten Absorptions- 